\title{
Modeling and Analysis the Impact of Unsymmetrical Bending on Aluminum Honeycomb Sandwich Beams with Polyester Resin/Glass Fibers Using Finite Element Method
}

\author{
Elhadj Ghelloudj \\ Department of Industrial Mechanics, SH/DP Regional Direction Haoud Berkaoui, Ouargla 30000, Algeria
}

Corresponding Author Email: hadjhadj105@gmail.com

https://doi.org/10.18280/rcma.303-409

Received: 9 May 2020

Accepted: 3 June 2020

\section{Keywords:}

CAST3M, honeycomb, numerical modeling, sandwich structures, unsymmetrical bending

\begin{abstract}
Sandwich structures are low-weight and have the best stiffness and a relatively high flexural strength, what makes using them continues to increase rapidly for industrial applications ranging from aeronautics, road vehicles, satellites, ships and civil engineering to mention only a few. The paper presents investigation and analysis of the behavior of composite sandwich beams with polyester resin/glass fibers skins (T800/M300) and aluminum honeycomb core under unsymmetrical bending impact. In this work we propose a numerical study using a calculation software, structural analysis by finite element method (CAST3M), for determining the stresses and displacements. The results which have been obtained after numerical modeling showed that unsymmetrical bending resistance of the sandwich beam is dependent largely on the skins.
\end{abstract}

\section{INTRODUCTION}

A sandwich material is a special class of composite material $[1,2]$. By sandwich structure we mean an element consisting of two, stiff, strong layers, called leathers or faces, spaced apart and rigidly connected to a connective element which takes the name of core [3-6] (e.g. foam, honeycomb and balsa wood), the structure thus composed has a static behavior considerably better than the individual parts that make up. Lightweight sandwich constructions are used to increase the specific stiffness, which formulate the strengthening of structures for functional and economic reasons $[7,8]$. The face carries tensile and compressive stresses, whereas the core carries transverse forces as well as shear stresses [9].

The principle of sandwich construction is well established in the fields of shipbuilding and aerospace technology $[10,11]$. Nowadays, sandwich panels can be found in many other technological fields such as in high-speed ferries, high-speed passenger trains [12], marine industry [13], building industry [14] or automotive applications [15, 16]. Especially in the naval industry [17], there is a strong trend to use sandwich shells in the construction of ship hulls. Other innovative examples include civil engineering structures such as highway bridge decks [18], due to their superior advantages of lightweight, high rigidity, low thermal conductivity and high strength to weight ratio [19-21]. Traditionally, lightweight core materials such as foam core, truss core, honeycomb core [22-24].

An effective understanding of mechanical properties of the sandwich structural is very important for effective design [25]. Designers of sandwich structures must ensure that all potential failure modes are well considered in their analysis and investigation. The finite element method (FEM) is a common and most effective tool for structural analysis of sandwich construction [26, 27].

There have been many investigations aiming the modeling of the behavior of sandwich beam under Bending load [28-30] has been extensively investigated for both the static 3-Point Bending [31-35] and static 4-Point Bending [36-39]. There are also different studies with respect to the modeling of honeycomb sandwich structures especially [40, 41]. In recent times finite element analysis has become a popular tool to determine the elastic properties of honeycomb materials, this has led many researchers to developed a $3 \mathrm{D}$ finite elementbased model to determine the elastic properties of core materials [42-47]. However, no systematic investigations had not been addressed on the modeling of the behavior of honeycomb sandwich beams under unsymmetrical bending by finite element method.

The purpose of the present work is to present a numerical study based on finite element method to determine the effect of unsymmetrical bending on properties of sandwich beams such as stresses $\left(\sigma_{\mathrm{xx}}, \sigma_{\mathrm{yy}}\right.$ and $\left.\tau_{\mathrm{xy}}\right)$, displacement to axis $\mathrm{X}$, displacement to axis $\mathrm{Y}$ at different angles $\left(30^{\circ}, 45^{\circ}, 60^{\circ}\right.$ and $\left.90^{\circ}\right)$. The behavior of our numerical model during unsymmetrical bending using FEM by software CAST3M is analyzed and the role played by different simulation conditions (angles and loads) in mechanical properties behaviors of the honeycomb sandwiches made from woven polyester resin/glass fibers facesheets and aluminum honeycomb core is discussed. Finally, results are compared according to effect of angles and loads variations.

The main goal of the current study is to investigate the impact behavior of sandwich composite that can be used for safety important structures. Thus, it can be developed a new composite material with optimal physical and mechanical properties. 


\section{MATERIALS AND METHODS}

\subsection{Description of material}

Material which used in this research prepared from Aluminium for the honeycomb core of sandwich material and polyester resin/glass fibers (T800/M300) for the skins material. The dimensions and geometry of honeycomb sandwich structure is given in Figure 1, The mechanical properties of the basic materials are summarized in Tables 1 and 2 . The behaviour of cellular materials theory was given by Gibson and Ashby [48].

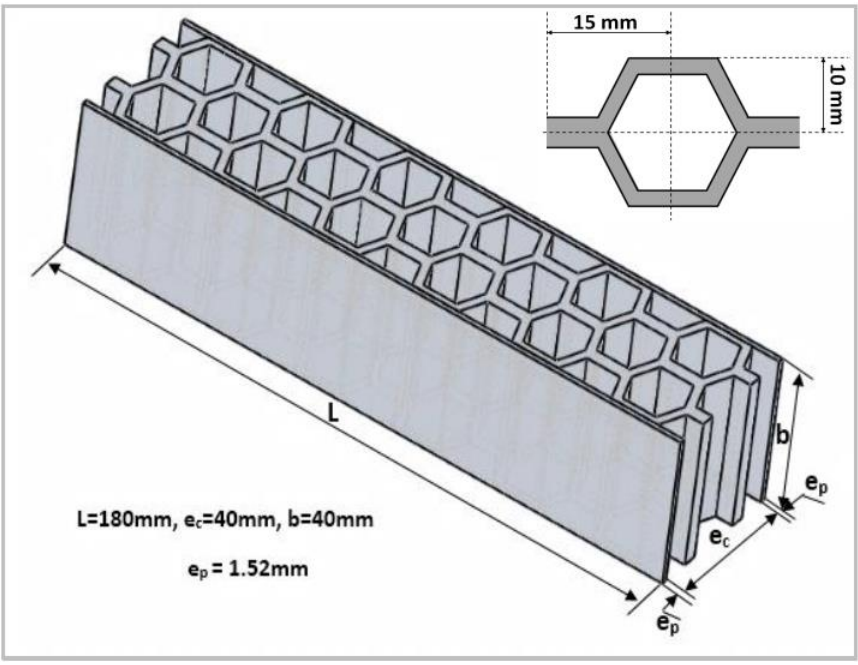

Figure 1. Schematic model of honeycomb core sandwich beam

Table 1. Mechanical properties of polyester resin/glass fibers (T800/M300)

\begin{tabular}{cc}
\hline Young's modulus (MPa) & 6385 \\
\hline Tensile strength (MPa) & 21 \\
\hline Shear modulus (MPa) & 2105 \\
\hline Face thickness $(\mathbf{m m})$ & 1.52 \\
\hline Poisson's ration & 0.16 \\
\hline
\end{tabular}

Table 2. Mechanical properties of Al honeycomb core

\begin{tabular}{cc}
\hline Young modulus E (MPa) & Poisson's ration v \\
\hline $\mathbf{7 0 0 0 0}$ & 0.33 \\
\hline
\end{tabular}

\subsection{Finite element simulations}

In this work we propose a numerical study using a calculation software, structural analysis by finite element method (CAST3M). For determining behaviour of the stresses $\left(\sigma_{\mathrm{xx}}, \sigma_{\mathrm{yy}}\right.$ and $\left.\tau_{\mathrm{xy}}\right)$ and displacements (UX and UY) of the honeycomb sandwich beams exposed to the impact of unsymmetrical bending as shown in Figure 2, the sandwich beam is subjected to unsymmetrical bending by a concentrated load equal with $\left(\mathrm{F}=\mathrm{I}^{*} \mathrm{DF}\right.$ with $\left.\mathrm{i}=1,2 . .10\right)$ and different angles $\left(30^{\circ}, 45^{\circ}, 60^{\circ}\right.$ and $\left.90^{\circ}\right)$. CAST3M is a computer code for analysis of structures with the help of finite element method, it has a private programming language called "GIBIANE".

This code was developed by the "Department of Mechanical Technology (DMT) of the French, Commission of Atomic Energy (CEA) in France". The purpose of the development of CAST3M is to provide high level support for design, dimensioning and analysis of structures and components in the mechanics research field. In this context, CAST3M incorporates not only the process of calculations, but also presents a complete system, integrating the calculation functions themselves and functions of model construction (pre-treatment) and result processing (post-treatment).

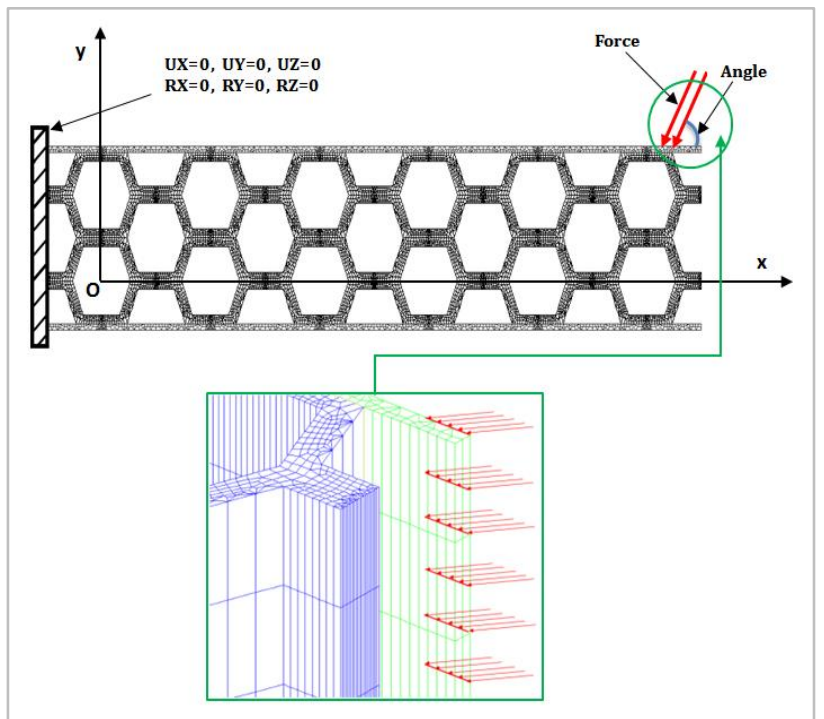

Figure 2. Geometry of the unsymmetrical bending test and simulation conditions

\subsection{FEM meshing of the model}

In CAST3M, a polygon mesh or polymesh is a collection of vertices and triangles that define the shape of a polyhedral object. The aim of the polygon mesh is to discrete geometrically the field of analysis in order to be able to later associate a formulation finite element to support geometric.

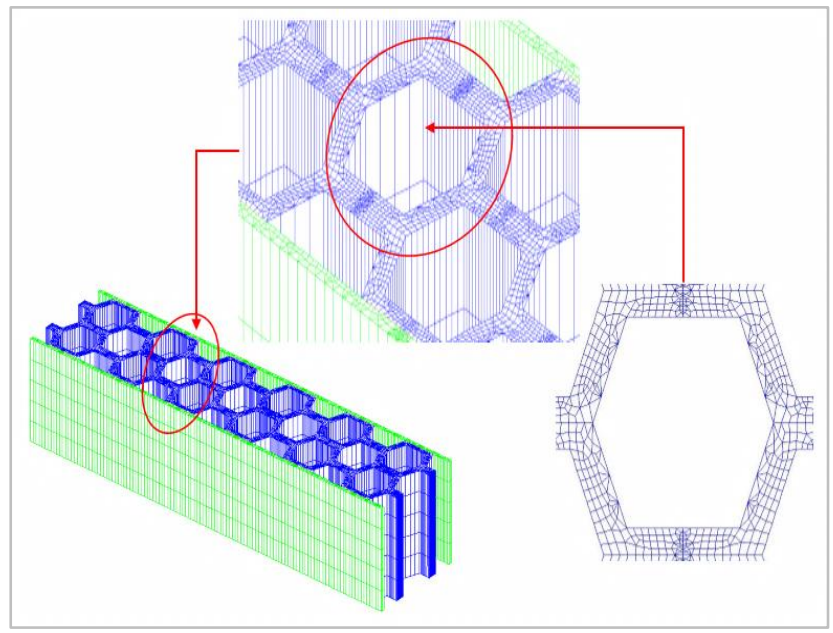

Figure 3. FEM meshing of the studied model

We have chosen into this study standard elements CUB8 for the mesh of sandwich beams with 53964 nodes and 44640 elements. This mesh has the side surfaces plane and parallel and be used for 3-D modeling of solid structures. This element has eight nodes with three degrees of freedom at each node: translations in the nodal $\mathrm{x}, \mathrm{y}$, and $\mathrm{z}$ directions. Once all the element attributes were given the model was meshed using the mesh tool. The meshed of the model presented in the Figure 3 are realized using the specialized software CAST3M. 


\subsection{Flowchart of CAST3M program}

The main purpose of a flowchart is to analyse different processes. In CAST3M, A flowchart is the graphical or pictorial representation of a finite element analysis with the help of different symbols of simulation conditions, shapes and arrows in order to demonstrate a process of modelling of sandwich beams under unsymmetrical bending. Figure 4 shows the flowchart of a finite element analysis with CAST3M.

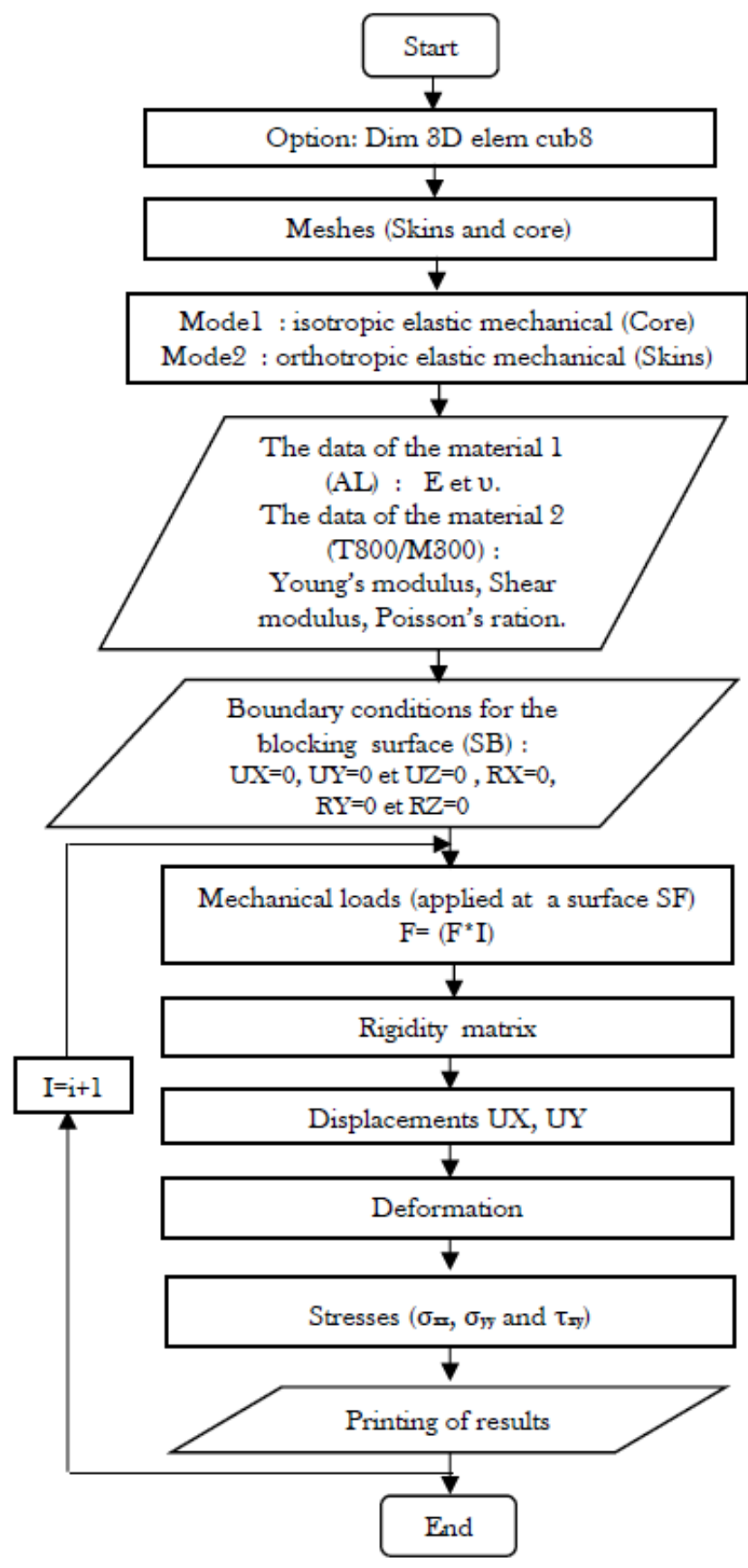

Figure 4. Flowchart of a FE analysis with CAST3M

\subsection{Sensing points}

Sensing points are the points that are placed in the geometry of the sandwich beam under this study in order to track the evolution of stresses $\left(\sigma_{\mathrm{xx}}, \sigma_{\mathrm{yy}}\right.$ and $\left.\tau_{\mathrm{xy}}\right)$ displacement to axis $\mathrm{X}$, displacement to axis Y. Figure 5 specifically shows the sensing points for the considered model (pk1, pk2 represent the skins and $\mathrm{pk} 3, \mathrm{pk} 4$ represent the honeycomb core). The coordinates of the points of sensing of model are summarized in Table 3.

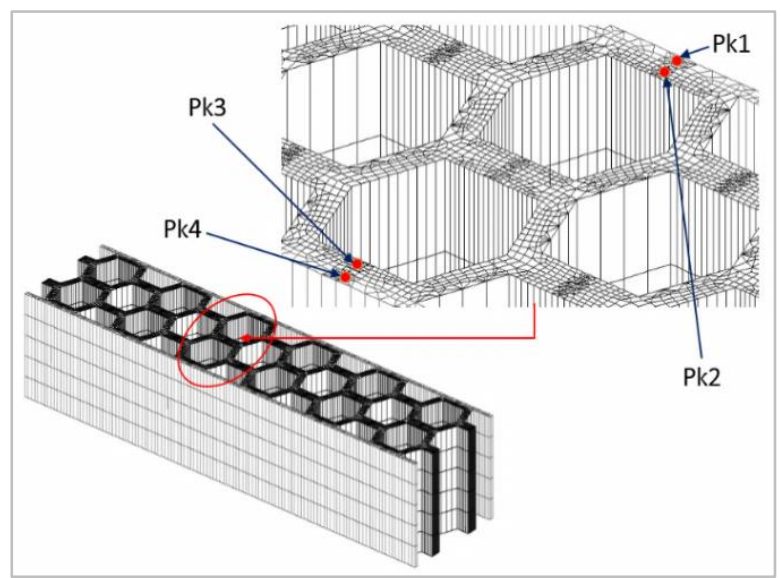

Figure 5. Distribution of the sensing points of the studied sandwich beam model

Table 3. Coordinates of the sensing points

\begin{tabular}{|c|c|c|c|c|}
\hline Points of Sensing & \multicolumn{3}{|c|}{ The coordinates } & $\mathbf{N}^{\circ}$ node \\
\hline $\begin{array}{c}\text { Pk1 } \\
\text { (skin 1) }\end{array}$ & $\mathrm{X}(\mathrm{mm})$ & $\mathrm{Y}(\mathrm{mm})$ & $\mathrm{Z}(\mathrm{mm})$ & 53412 \\
\hline $\begin{array}{c}\text { Pk2 } \\
\text { (core) }\end{array}$ & 60.000 & 30.760 & 40.000 & 52914 \\
\hline $\begin{array}{c}\text { Pk3 } \\
\text { (core) }\end{array}$ & 60.000 & 29.000 & 40.000 & 52333 \\
\hline $\begin{array}{c}\text { Pk4 } \\
\text { (skin 2) }\end{array}$ & 60.000 & -9.000 & 40.000 & 53320 \\
\hline
\end{tabular}

\section{RESULTS AND DISCUSSION}

Figure 6 indicates the evolution of the stresses $\left(\sigma_{x x}, \sigma_{y y}\right.$ and $\tau_{\mathrm{xy}}$ ) versus the loads of sandwich materials at different angles of $30^{\circ}, 45^{\circ}, 60$ and $90^{\circ}$. We found almost the same behavior for all the unsymmetrical bending properties (stresses $\sigma_{x x}, \sigma_{y y}$ and $\tau_{\mathrm{xy}}$ ) at sensing points (pk1, pk2, pk3 and pk3) obtained by the 3D finite element model, where we observed increase in the values of stresses when the values of loads is increased, for example, the value of $\sigma_{\mathrm{xx}}$ has increased from 2,3099 MPa to $9,3794 \mathrm{MPa}$ by $306 \%$ between 3 and $10 \mathrm{KN}$, on the other hand, the value of $\sigma_{y y}$ also has increased from $0.81156 \mathrm{MPa}$ to $10,087 \mathrm{MPa}$ by $1142 \%$ between 3 and $10 \mathrm{KN}$. This previous result is based on behavior of $\mathrm{pk} 2$ and $\mathrm{pk} 3$ at $30^{\circ}$ and $60^{\circ}$, Respectively.

It's clear that there are different behavior of the stresses $\left(\sigma_{x x}\right.$, $\sigma_{\mathrm{yy}}$ and $\left.\tau_{\mathrm{xy}}\right)$, where there are higher increases of the stresses values in the core (pk2 and $\mathrm{pk} 3$ ) than those in skins ( $\mathrm{pk} 1$ and $\mathrm{pk} 4$ ) of the sandwich beam model, for example, the $\sigma_{\mathrm{xx}}$ values in the core are in the range of 1,585-21,431 MPa for the an angle $45^{\circ}$ at different loads (from 1 to 10 ) $\mathrm{KN}$, while $\sigma_{\mathrm{xx}}$ values in the skins are in the range of $0.07469-1.0656 \mathrm{MPa}$ for the same angle and loads. according this figure, it can be said that the unsymmetrical bending resistance is much higher in the skins than the core for sandwich beam, from this point we say that the unsymmetrical bending resistance of the sandwich beam is dependent largely on the skins. Overall, these findings are in accordance with what has been found in previous studies $[49,50]$. They found the unsymmetrical bending resistance of sandwich materials depends on the skins larger than in the honeycomb core. 

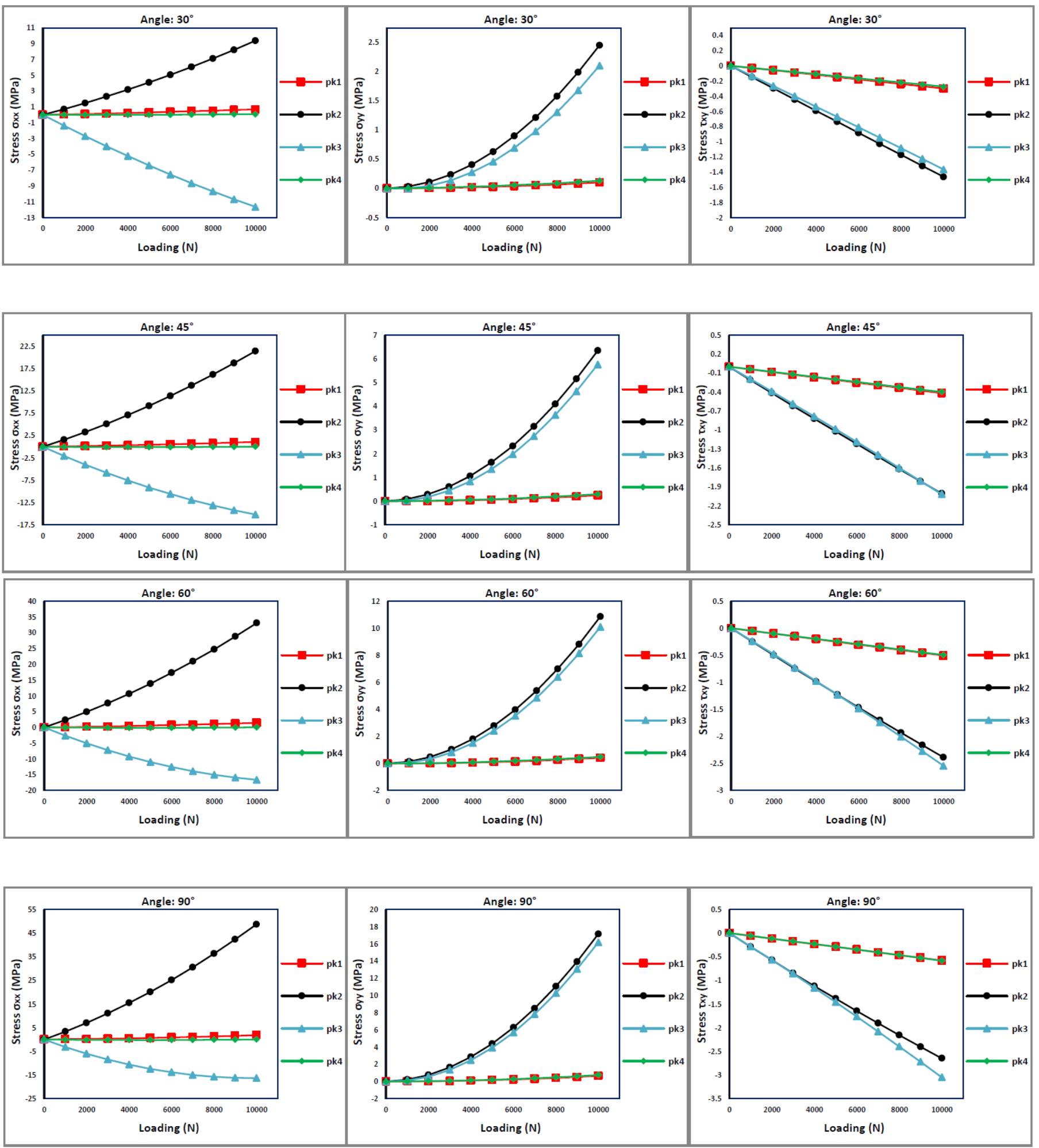

Figure 6. The evolution of the stresses $\left(\sigma_{\mathrm{xx}}, \sigma_{\mathrm{yy}}\right.$ and $\left.\tau_{\mathrm{xy}}\right)$ obtained by finite element

Critical points or maximum stress values after the effect of bending on structure sandwich material can be predicted by the FEM simulation, Figure 7 shows the stresses $\left(\sigma_{\mathrm{xx}}, \sigma_{\mathrm{yy}}\right.$ and $\left.\tau_{\mathrm{xy}}\right)$ distribution generated from the impact of unsymmetrical bending on structure sandwich model $\left(30^{\circ}\right.$ at $\left.5 \mathrm{KN}\right)$. This figure shows that the maximum stress values are concentrated in Aluminium honeycomb core and they are dissipated around the skins of structure sandwich material. This is confirming that the unsymmetrical bending resistance is much higher in the skins than the honeycomb core for sandwich beam.

Figure 8 illustrates the changes in the values of the stresses $\left(\sigma_{\mathrm{xx}}, \sigma_{\mathrm{yy}}\right.$ and $\left.\tau_{\mathrm{xy}}\right)$ at various angles of sandwich beam model during unsymmetrical bending. Each values stress showed a nonlinear elastic behaviour until a maximum angle, it can be observed an important increase in the values of the stresses when angles increasing. we observed also the values of $\sigma_{\mathrm{xx}}$ is the largest, then the values of $\sigma_{\mathrm{yy}}$, then the values of $\tau_{\mathrm{xy}}$. For example, the $\sigma_{\mathrm{xx}}$ value is $33 \mathrm{MPa}$ at $60^{\circ}$, while the value of $\sigma_{\mathrm{yy}}$ and $\tau_{\mathrm{xy}}$ is $15 \mathrm{MPa},-2.25 \mathrm{MPa}$, respectively. The maximum stress values for $\sigma_{\mathrm{xx}}, \sigma_{\mathrm{yy}}$ and $\tau_{\mathrm{xy}}$ after the effect of unsymmetrical bending on structure sandwich material was obtained when the angle is $90^{\circ}$, for this can be said that the 
simple bending the bigger influence compared to the unsymmetrical bending.

Figure 9 shows the contours of deformation of sandwich beam during unsymmetrical bending obtained by finite element simulation using CAST3M. After simulating the bending and various results, it can be seen that the behavior of sandwich beam is clearly shown (deformation increases with increasing loads).

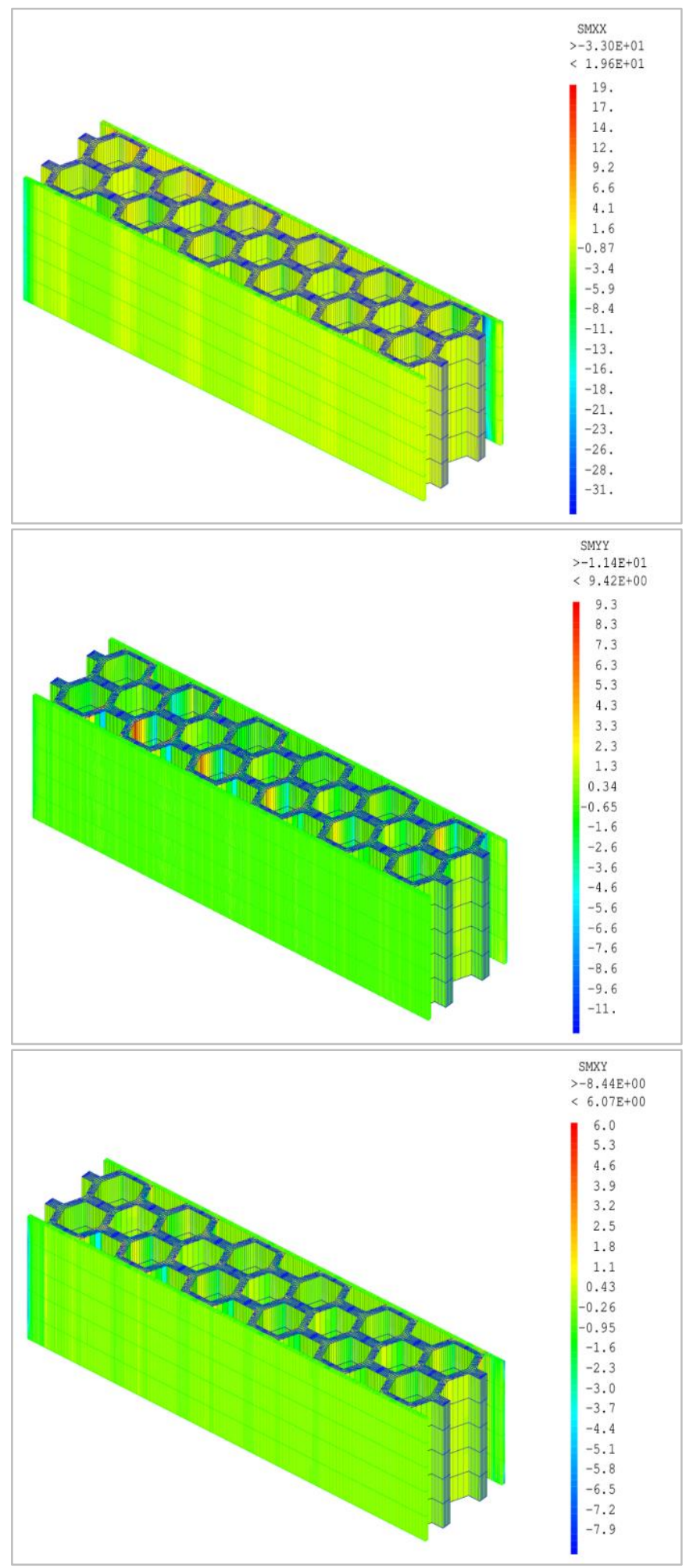

Figure 7. Finite element analysis results $\left(\sigma_{\mathrm{xx}}, \sigma_{\mathrm{yy}}\right.$ and $\left.\tau_{\mathrm{xy}}\right)$ of sandwich beams $\left(30^{\circ}\right.$ at $\left.5 \mathrm{KN}\right)$

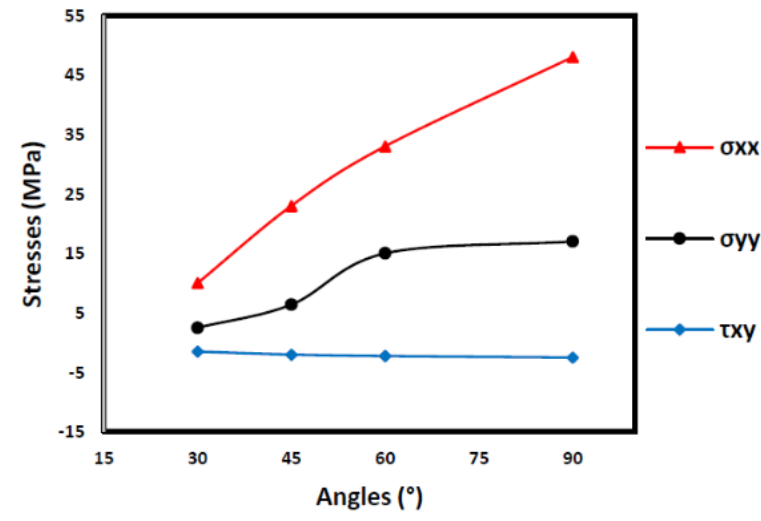

Figure 8. The evolution of the stresses $\left(\sigma_{x x}, \sigma_{y y}\right.$ and $\left.\tau_{x y}\right)$ at various angles obtained by finite element (at $10 \mathrm{KN}$ )

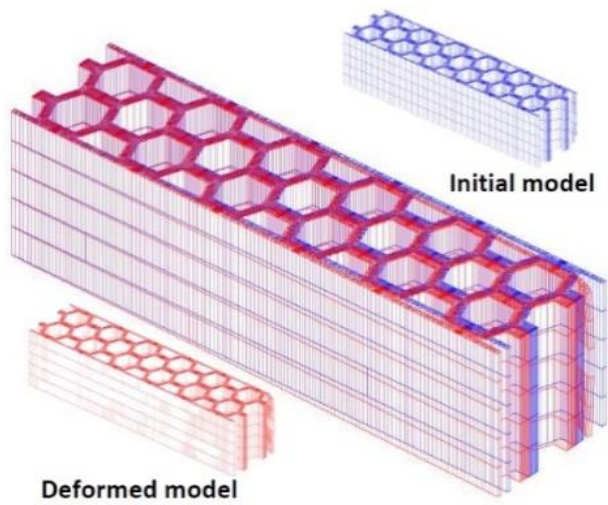

Figure 9. Deformation of sandwich beam model under unsymmetrical bending $\left(30^{\circ}\right.$ at $\left.5 \mathrm{KN}\right)$
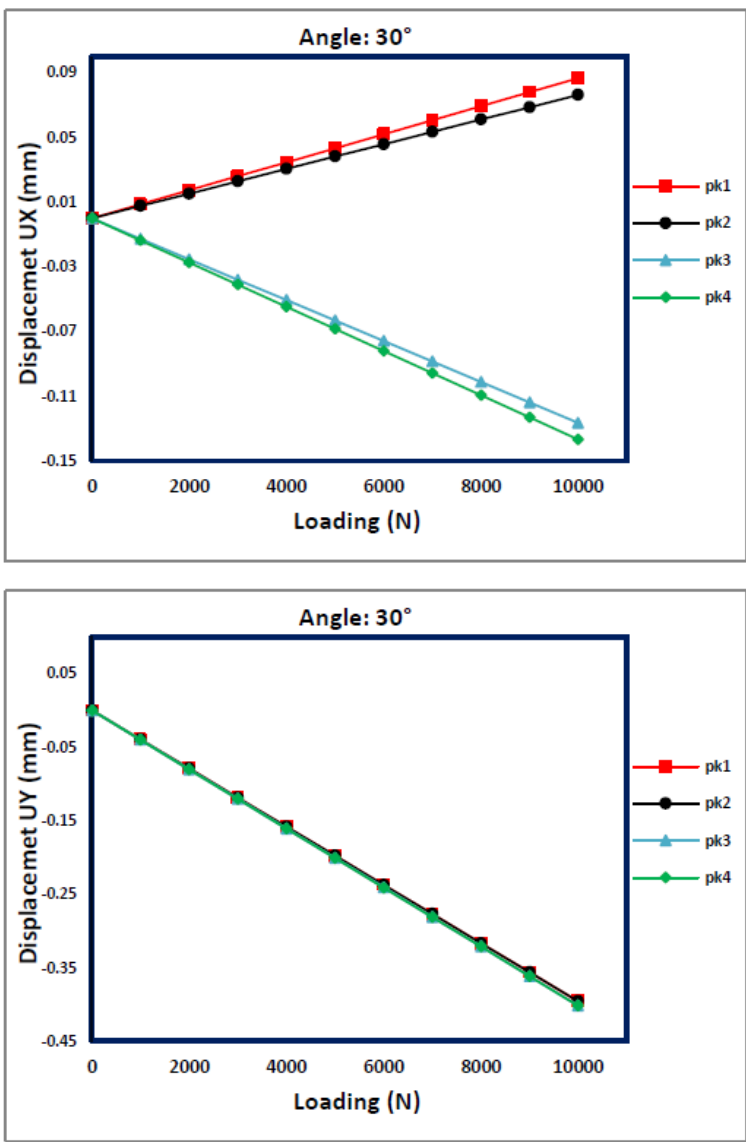

Figure 10. The evolution of the displacements (UX and UY) at $30^{\circ}$ obtained by finite element 
Figure 10 shows the curve of the displacements (UX and UY) of sandwich composite beam in unsymmetrical bending under various loads ( 1 to 10$) \mathrm{KN}$ at $30^{\circ}$. From the Figure 10 , it can be seen that the displacements increase with increasing loads. can be observed also the same linear evolution of the displacements in the skin and honeycomb core, for example, the UX values in the core are in the range of $0,00763-0,07631$ $\mathrm{mm}$ for different loads (from 1 to 10 ) $\mathrm{KN}$, while UX values in the skins are in the range of $0,00866-0,08665 \mathrm{~mm}$ for the same loads (Positive direction). As for the UY values are in the range of $-0,0396$ to $-0,39596 \mathrm{~mm}$ for different loads (from 1 to 10$) \mathrm{KN}$ for both skins and core (Negative direction). This indicates that the displacement to the axis $\mathrm{X}$ is symmetric between pk1, pk2 and pk3, pk4, at variance the displacement to axis Y. unsymmetrical bending under various angles at different loads is the cause of change the position of neutral axis $\left(\sigma_{\mathrm{xx}}=0 \mathrm{MPa}\right)$

\section{CONCLUSIONS}

The behaviour under impact unsymmetrical bending of the composite sandwich beams made from woven polyester resin/glass fibers (T800/M300) facesheets and Aluminium hexagonal honeycomb core was investigated using a threedimensional finite element model implemented in CAST3M. Based on the results obtained, the most important relationships derived are as follows: This study gives a guideline to model the sandwich beams and to predict the failure modes. The stresses $\left(\sigma_{\mathrm{xx}}, \sigma_{\mathrm{yy}}\right.$ and $\left.\tau_{\mathrm{xy}}\right)$ increase when the loads and angles increasing from the unsymmetrical bending. The unsymmetrical bending resistance is much higher in the skins than the honeycomb core for sandwich material. The displacements increase with increasing loads. Unsymmetrical bending under various angles at different loads is the cause of change the position of neutral axis.

The future objective of this research work is to compare this type of sandwich beams model with other models in order to analyze and study the mechanical properties under unsymmetrical bending.

\section{ACKNOWLEDGMENT}

This research has been supported by the maintenance division, SH/DP Regional Direction Haoud Berkaoui, Ouargla, Algeria. I thank my friends at the Department of industrial mechanics and all researchers worldwide.

\section{REFERENCES}

[1] Arbaoui, J., Schmitt, Y., Pierrot, J.L., Royer, F.X. (2014) Effect of core thickness and intermediate layers on mechanical properties of polypropylene honeycomb multi-layer sandwich structures. Archives of Metallurgy and Materials, 59(1): 11-16. http://dx.doi.org/10.2478/amm-2014-0002

[2] Piollet, E., Fotsing, E.R., Ross, A., Michon, G. (2019). High damping and nonlinear vibration of sandwich beams with entangled cross-linked fibres as core material. Composites Part B, 168: 353-366. https://doi.org/10.1016/j.compositesb.2019.03.029

[3] Tiantian, L., Lifeng, W. (2017). Bending behavior of sandwich composite structures with tunable 3D-printed core materials. Composite Structures, 175: 46-57. https://doi.org/10.1016/j.compstruct.2017.05.001

[4] Krishanu, G., Prasun, C., Chiranjit, B. (2020). Study of modal behavior of sandwich structure with various core materials an analytical approach. Revue des Composites et des Matériaux Avancés-Journal of Composite and Advanced $\quad$ Materials, 30(1): 15-21. https://doi.org/10.18280/rcma.300103

[5] Zhi, S., Dong, L., Weisheng, Z., Shanshan, S., Xu, G. (2017). Topological optimization of biomimetic sandwich structures with hybrid core and CFRP face sheets. Composites Science and Technology, 142: 79-90. https://doi.org/ 10.1016/j.compscitech.2017.01.029

[6] Abbadi, A., Koutsawa, Y., Carmasol, A., Belouettar. S., Azari, Z. (2009). Experimental and numerical characterization of honeycomb sandwich composite panels. Simulation Modelling Practice and Theory, 17 (10):

$1533-1547$ https://doi.org/10.1016/j.simpat.2009.05.008

[7] Li, C., Shen, H.S., Wang, H. (2019). Nonlinear bending of sandwich beams with functionally graded negative Poisson's ratio honeycomb core. Composite Structures, 212: 317-325. https://doi.org/10.1016/j.compstruct.2019.01.020

[8] Tie, B., Tian, B.Y., Aubry, D. (2016). Theoretical and numerical modeling of membrane and bending elastic wave propagation in honeycomb thin layers and sandwiches. Journal of Sound and Vibration, 382: 100121. https://doi.org/10.1016/j.jsv.2016.06.027

[9] Galletti, G.G., Vinquist, C., Es-Said, O.S. (2008). Theoretical design and analysis of a honeycomb panel sandwich structure loaded in pure bending. Engineering Failure Analysis, 15(5): 555-562. https://doi.org/10.1016/j.engfailanal.2007.04.004

[10] Fan, X., Li, Y., Li, J., Yan, C., Li, K. (2009). Modeling of heat conduction in thermoplastic honeycomb core/face sheet fusion bonding. Chinese Journal of Aeronautics, 22(6): $\quad$ 685-690. https://doi.org/10.1016/s10009361(08)60159-4

[11] Pandyaraj, V., Rajadurai, A., Anand, G. (2018). Experimental investigation of compression strength in novel sandwich structure. Materials Today: Proceedings, $5(2)$ : $8625-8630$ https://doi.org/10.1016/j.matpr.2017.11.561

[12] Han, Q.G., Qin, H.L., Liu, Z.H., Han, Z.W., Zhang, J.Q., Niu, S.C., Zhang, W.Q., Sun, Y.B., Shi, S.Q. (2020). Experimental investigation on impact and bending properties of a novel dactyl-inspired sandwich honeycomb with carbon fiber. Construction and Building Materials, 253: 119161 https://doi.org/10.1016/j.conbuildmat.2020.119161

[13] Palomba, G., Crupi, G., Epasto, G. (2019). Collapse modes of aluminium honeycomb sandwich structures under fatigue bending loading. Thin-Walled Structures, 145: 106363. https://doi.org/10.1016/j.tws.2019.106363

[14] Jen, Y.M., Chang, L.Y. (2008). Evaluating bending fatigue strength of aluminum honeycomb sandwich beams using local parameters. International Journal of Fatigue, $\quad 30(6)$ : $1103-1114$ https://doi.org/10.1016/j.ijfatigue.2007.08.006

[15] Bastos, SF., Borges, L., Rochinha, F.A. (2002). Numerical and experimental approach for identifying elastic parameters in sandwich plates. Shock and 
Vibration,

9(4-5):

193-201

https://doi.org/10.1155/2002/617913

[16] Li, M., Deng, Z., Guo, H., Liu, R., Ding, B. (2014). Optimizing crashworthiness design of square honeycomb structure. Journal of Central South University, 21: 912-919. https://doi.org/10.1007/s11771014-2018-0

[17] Gustin, J., Joneson, A., Mahinfalah, M., Stone, J. (2005). Low velocity impact of combination Kevlar/carbon fiber sandwich composites. Composite Structures, 69(4): 396406. https://doi.org/10.1016/j.compstruct.2004.07.020

[18] Morcous, G., Cho, Y., El-Safty, A., Chen, G.M. (2010). Structural behavior of FRP sandwich panels for bridge decks. KSCE Journal of Civil Engineering, 14(6): 879888. https://doi.org/10.1007/s12205-010-1025-4

[19] Kers, J., Pohlak, M., Majak, J., Eerme, M., Pabut, O., Herranen, H., Saarna, M., Allikas, G., Aruniit, A. (2012). Design and testing of sandwich structures with different core materials. Materials Science, 18(1): 45-50. https://doi.org/10.5755/j01.ms.18.1.1340

[20] Meng, L., Lan, X.Q., Zhao, J., Wang, Z.M. (2020). Equivalent models and mechanical properties of bioinspired corrugated sandwich structures subjected to bending loads. Composite Structures, 244: 112257. https://doi.org/10.1016/j.compstruct.2020.112257

[21] Xu, F., Qiao, P.Z. (2002). Homogenized elastic properties of honeycomb sandwich with skin effect. International Journal of Solids and Structures, 39(8): 2153-2188. https://doi.org/10.1016/s00207683(02)00111-7

[22] Sun, Y., Guo, L.C., Wang, T.S., Zhong, S.Y., Pan, H.Z. (2018). Bending behavior of composite sandwich structures with graded corrugated truss cores. Composite Structures, $\quad$ 185: 446-454. https://doi.org/10.1016/j.compstruct.2017.11.043

[23] Birman, V., Kardomateas, G.A. (2018). Review of current trends in research and applications of sandwich structures. Composites Part B, 142: 221-240. https://doi.org/10.1016/j.compositesb.2018.01.027

[24] Jin, M.M., Hu, Y.C., Wang, B. (2015). Compressive and bending behaviours of wood-based two-dimensional lattice truss core sandwich structures. Composite Structures, 124: 337-344. https://doi.org/10.1016/j.compstruct.2015.01.033

[25] Jörg, F., Torsakul, S., Brezing, A., Sivakumara, K. (2008). Materials Technology for Climate Change \& 5th Thailand Materials Science and Technology Conference, Thailand, pp. 79-81.

[26] Buitrago, B.L., Santiuste, C., Sánchez-Sáez, S., Barbero, E., Navarro, C. (2010). Modelling of composite sandwich structures with honeycomb core subjected to high-velocity impact. Composite Structures, 92(9): 2090-2096.

https://doi.org/10.1016/j.compstruct.2009.10.013

[27] Lu, C., Zhao, M.Y., Jie, L., Wang, J., Gao, Y., Cui, X., Chen, P. (2015). Stress distribution on composite honeycomb sandwich structure suffered from bending load. Procedia Engineering, 99: 405-412. https://doi.org/10.1016/j.proeng.2014.12.554

[28] Mohammadabadi, M., Yadama, V., Smith, L. (2019). An analytical model for wood composite sandwich beams with a biaxial corrugated core under bending. Composite Structures, 228 :

111316 https://doi.org/10.1016/j.compstruct.2019.111316
[29] D’Ottavio, M., Dozio, L., Vescovini, R., Polit, O. (2016). Bending analysis of composite laminated and sandwich structures using sublaminate variable-kinematic Ritz models. Composite Structures, 155: 45-62. https://doi.org/10.1016/j.compstruct.2016.07.036

[30] Baho, O., Zergoune, Z., Ichchou, M.N., Harras, B., Benamar, R., Troclet, B., Bareille, O. (2016). On global bending-shear core transition effects for the vibroacoustic of sandwich structures: Analytical and numerical investigations. Composite Structures, 154: 453-463. https://doi.org/10.1016/j.compstruct.2016.07.062

[31] Iyer, S.V., Chatterjee, R., Ramya, M., Suresh, E., Padmanabhan, K. (2018). A comparative study of the three point and four point bending behaviour of rigid foam core glass/epoxy face sheet sandwich composites. Materials Today: Proceedings, 5(5): 12083-12090. https://doi.org/10.1016/j.matpr.2018.02.184

[32] Cheneler, D., Kennedy, A.R. (2020). Measurement and modelling of the elastic defection of novel metal syntactic foam composite sandwich structures in 3-point bending. Composite Structures, 235: 111817. https://doi.org/10.1016/j.compstruct.2019.111817

[33] Yu, Y., Ying, L., Hou, W.B., Hu, P., Jia, X.X., Akhmet, G. (2008). Failure analysis of adhesively bonded steel corrugated sandwich structures under three-point bending. Composite Structures, 184: 256-268. https://doi.org/10.1016/j.compstruct.2017.10.011

[34] Yan, L.L., Han, B., Yu, B., Chen, C.Q., Zhang, Q.C., Lu, T.J. (2014). Three-point bending of sandwich beams with aluminum foam-filled corrugated cores. Materials and Design, 60: 510-519. https://doi.org/10.1016/j.matdes.2014.04.014

[35] Julien, B., François, X.H., Nathalie, G., Pascal, R. (2014). Suivi par émission acoustique de structure sandwich composite/nid d'abeille lors de sollicitation en flexion 3 points. Analyse de la dynamique des précurseurs de la rupture. Revue des Composites et des Matériaux Avancés-Journal of Composite and Advanced Materials, 24(4): 393-402. https://doi.org/10.3166/rcma.24.393402

[36] Perret, O., Lebée, A., Douthe, C., Sab, K. (2018). Experimental determination of the equivalent-layer shear stiffness of CLT through four-point bending of sandwich beams. Construction and Building Materials, 186: 11321143. https://doi.org/10.1016/j.conbuildmat.2018.07.102

[37] Sayahlatifi, S., Rahimi, G.H., Bokaei, A. (2020). The quasi-static behavior of hybrid corrugated composite/balsa core sandwich structures in four-point bending: Experimental study and numerical simulation. Engineering $\quad$ Structures, 210: 110361. https://doi.org/10.1016/j.engstruct.2020.110361

[38] Zhou, G., Leung, H.L., Robinson, B., Zheng, C. (2019). New method for the evaluation of residual compressive strengths of sandwich panels via four-point bending. Mechanics of Materials, 136: 103075. https://doi.org/10.1016/j.mechmat.2019.103075

[39] Lagunegrand, L., Lorriot, T., Harry, R., Wargnier, H. (2006). Design of an improved four point bending test on a sandwich beam for free edge delamination studies. Composites: Part B, 37(2-3): 127-136. https://doi.org/10.1016/j.compositesb.2005.07.002

[40] Talischi, C., Paulino, G.H., Le, C.H. (2009). Honeycomb 
Wachspress finite elements for structural topology optimization. Struct Multidisc Optim, 37: 569-583. https://doi.org/10.1007/s00158-008-0261-4

[41] Chen, C., Yan, N. (2006). Investigation of elastic moduli of kraft paper honeycomb core sandwich panels. Composites: Part B, 43(5): 2107-2114. https://doi.org/10.1016/j.compositesb.2012.03.008

[42] Asprone, D., Auricchio, F., Menna, C., Morganti, S., Prota, A., Reali, A. (2013). Statistical finite element analysis of the buckling behavior of honeycomb structures. Composite Structures, 105: 240-255. https://doi.org/10.1016/j.compstruct.2013.05.014

[43] Li, Y.M., Hoang, M.P., Abbes, B., Abbes, F., Guo, Y.Q. (2015). Analytical homogenization for stretch and bending of honeycomb sandwich plates with skin and height effects. Composite Structures, 120: 406-416. https://doi.org/10.1016/j.compstruct.2014.10.028

[44] Li, S.Q., Li, X., Wang, Z.H., Wu, G.Y., Lu, G.X., Zhao, L.M. (2016). Finite element analysis of sandwich panels with stepwise graded aluminum honeycomb cores under blast loading. Composites: Part A, 80: 1-12. https://doi.org/10.1016/j.compositesa.2015.09.025

[45] Liu, L.Q., Wang, H., Guan, Z.W. (2015). Experimental and numerical study on the mechanical response of Nomex honeycomb core under transverse loading.
Composite Structures, 121: 304-314. https://doi.org/10.1016/j.compstruct.2014.11.034

[46] Pan, B., Yu, L.P., Wu, D.F. (2015). Thermo-mechanical response of superalloy honeycomb sandwich panels subjected to non-steady thermal loading. Materials and Design, $\quad 88$ : 528-536. https://doi.org/10.1016/j.matdes.2015.09.016

[47] Roy, R., Park, S.J., Kweon, J.H., Choi, J.H. (2014). Characterization of Nomex honeycomb core constituent material mechanical properties. Composite Structures, 117:

255-266. https://doi.org/10.1016/j.compstruct.2014.06.033

[48] Masters, I.G., Evans, K.E. (2015). Models for the elastic deformation of honeycombs. Composite Structures, 35(4): 403-422. https://doi.org/10.1016/S02638223(96)00054-2

[49] Al-Fasih, M.Y., Kueh, A.B.H., Ibrahim, M.H.W. (2020). Failure behavior of sandwich honeycomb composite beam containing crack at the skin. PloS ONE, 15(2): 119. https://doi.org/10.1371/journal.pone.0227895

[50] Petras, A., Sutcliffe, M.P.F. (2000). Indentation failure analysis of sandwich beams. Composite Structures, 50 (3): 311-318. https://doi.org/10.1016/s02638223(00)00122-7 